\title{
Measuring Ratchet Effects within a Firm: Evidence from a Field Experiment varying Contractual Commitment
}

Charles Bellemanre

Bruce Shearer

mai / may 2014 


\section{Abstract}

We present results from a field experiment designed to measure the importance of managerial commitment to a contract within a firm that pays its workers piece rates. In the tree planting industry the piece rate paid to workers is determined as a function of the difficulty of the terrain to be planted. During the experiment, workers began planting a terrain at a trial piece rate, but were told this rate would be revised upwards if, after a few work days, average productivity was below that observed on a similar (control) terrain on which the firm had committed to the contract. Our results suggest that worker productivity was $20 \%$ to $40 \%$ lower in the absence of commitment. The reduction was less pronounced when workers had less time to benefit from any subsequent increase in the piece rate. This provides support for models of worker turnover as a means of overcoming ratchet effects.

Mots-clés : Ratchet effect, piece rates, incentive contracts, field experiments

Classification JEL : J33, M52, C93.

Bellemare : Département d'économique, Université Laval, CIRPÉE, IZA cbellemare@ecn.ulaval.ca

Shearer : Département d'économique, Université Laval, CIRPÉE, IZA, CIRANO bruce.shearer@ecn.ulaval.ca 


\section{Introduction}

Economic theory highlights the role of contractual commitment in determining the success of regulatory and incentive schemes in dynamic settings (Baron and Besanko, 1987; Laffont and Tirole, 1988). In the absence of commitment, contracts can be refined by principals to take advantage of the new information as it is revealed through production. This feedback induces forward looking agents to strategically withhold production (and information), anticipating its effect on their future payments or profits. The link between contracts and past performance has become known as the "ratchet principle" (Weitzman, 1980). The resulting inefficiency (or ratchet effect) in implementing piece-rate contracts has been blamed for their relative scarcity in the real economy; see Gibbons (1987) for a discussion and references. Yet economic theory also suggests institutions to counteract the ratchet effect in the absence of commitment. Ickes and Samuelson (1987) have shown that rotating workers across economic environments can be beneficial when information asymmetries exist over conditions that affect productivity. Rotating workers breaks the feedback from current output to future contracts for a particular worker, reducing the incentive to withhold output. ${ }^{1}$ Little is known as to either the economic importance of the ratchet effect in the real economy, or the ability of worker rotation to overcome these effects.

This paper measures the empirical importance of commitment and the ability of rotating workers to overcome the ratchet effect in the absence of commitment. We exploit a field experiment, conducted within a real economic firm to measure these effects. During the experiment the level of commitment to a contract was exogenously varied, allowing us to measure worker behaviour with and without commitment. We concentrate on worker output, measuring the extent to which workers withhold output in an effort to influence future piece rates. The experiment also varies the amount of time that workers expect to spend under revised future piece rates to identify the effect of worker rotation.

The experiment took place in a tree-planting firm that pays its workers piece rates. These workers plant trees on blocks of land that vary in the steepness and rockiness of the terrain. Typically, the piece rate paid to workers is determined as a function of the conditions on the terrain. Steep or rocky ground is more difficult to plant and slows planters down, forcing the firm to raise the piece rate to attract workers. These conditions are typically sampled by the manager before planting begins. The firm then commits to the piece-rate for the duration of planting on the block. During the experiment workers were told that the manager had not

\footnotetext{
${ }^{1}$ When information asymmetries exist over worker ability other institutions include developing worker commitment to stay in the firm (Lazear, 1986), and a well-functioning outside market for experienced workers (Kanemoto and Macleod, 1992).
} 
had time to sample the conditions on a particular (treatment) block, although he thought that they were similar to a (control) block that had been planted two weeks prior, under commitment to the piece-rate. In fact, the control and treatment blocks had been chosen by the manager as representing identical planting conditions. The workers were further told that the piece rate would be set on the treatment block at 16 cents per tree (the piece rate they had received on the control block) but if average productivity on the first two days of planting was below that on the control block, the piece rate would be increased, retroactively. This was repeated twice, on blocks of differing size. In both cases workers were told they would be planting on the treatment block until that block was completed: 10 days on the large block and 6 days on the small block.

We use the experimental data to measure the workers' reaction to a lack of commitment to the contract on the part of the firm. Since the control and treatment blocks were identical, any increase in the piece rate represents rents to the workers. We present theoretical results showing conditions under which forward-looking workers will withhold output on the treatment block (in the absence of commitment) in an effort to influence the piece rate and capture those rents. Rent-seeking behaviour is amplified on the larger block since the rents are enjoyed for a longer period of time. This is the effect of rotation. In the limit rents disappear by eliminating the second period and workers perfectly reveal conditions.

We compare daily productivity by the same workers on the treatment and control blocks to measure the empirical importance of contractual commitment. Our results show that combined productivity on both blocks decreased by $19 \%$ in the absence of commitment. This is consistent with recent studies which have considered the empirical importance of the ratchet effect in other settings (Charness, Kuhn and Villeval, 2011; Macartney, 2011; Levenson, Zoghi, Gibbs, and Benson, 2011). Our results also show that workers were less inclined to withhold output on the small block (a decrease of $15 \%$ versus $30 \%$ on the long block), suggesting that rotation can be an effective tool in overcoming the ratchet effect in the absence of commitment.

Finally, our results show that workers withheld more output on the second and third days of planting on the treatment block than on the first. Since workers had a better opportunity to communicate with each other after the first day of planting, this is consistent with workers cooperating in revealing conditions to the firm, something that our theoretical model assumes.

The rest of the paper is organized as follows. The next section describes institutional details of the tree-planting industry and the firm in which the experiment was conducted. Section 2 presents the design of the experiment. Section ?? presents the model. Section 3 presents the data and our main empirical results. Section 4 concludes. 


\section{Experimental design}

The experiment took place on two separate treatment planting blocks, denoted $T_{L}$ and $T_{S}$, both planted in June, 2010. These blocks differed in size and the number of planters assigned to them. Block $L$ was planted by 8 planters and was scheduled to be planted over a period of 10 days. $^{2}$ Block $S$ had 15 planters assigned to it and was scheduled to be planted over a period of 5 days. Both $T_{L}$ and $T_{S}$ blocks would normally have been planted at a piece rate of $\$ 0.16$ per tree.

Prior to the experiment the manager chose a control block for each of treatment block, matched on the basis of planting conditions. These are denoted $C_{L}$ (matched to $T_{L}$ ) and $C_{S}$ (matched to $T_{S}$ ), respectively. The control blocks were each planted under commitment the manager announced the piece rate (as usual) at the beginning of planting on the block. The piece rate was $\$ 0.16$ per tree.

Prior to planting on each of the experimental blocks, the workers were told by the manager that he had not yet viewed the block in detail and hence had not set a piece rate. They were further told that the manager thought the land was similar to the control block and would therefore start them planting at the same piece rate as had been paid on the control block. They were also told that the manager would check production levels after 2 or 3 days ${ }^{3}$ and would increase the piece rate if average production was below that observed on the control block; the increased piece rate would then apply (retroactively) for all planting performed on the treatment block. Finally, the manager told the planters how many days they would be on planting on the block: 10 days for $T_{L}$ and 5 days for $T_{C}$. The amount by which the rate would be increased was left unspecified.

An important aspect of our design is that workers were unaware that they were participating in an experiment. ${ }^{4}$ This allowed us to observe their reaction in the absence of commitment within their natural work environment. To this end, planters were told that the treatment blocks had just recently been added to the contract, giving the manager little time for detailed viewing of the conditions of the terrain. What is more, the manager was not going to have time to view the terrain in detail during the next few days as he was busy viewing other terrains. ${ }^{5}$

The manager was also instructed to treat the experimental days as normal working days:

\footnotetext{
${ }^{2}$ The block was unexpectedly expanded to include neighbouring land once the non-commitment faze was completed. This gave 7 extra days of planting (and observations).

${ }^{3}$ Two days of comparison were used on treatment block $S$ and three days on treatment block $L$.

${ }^{4}$ This is common practice in field experiments; see, for example, Gneezy and List, 2006.

${ }^{5}$ None of the planters questioned this explanation. The reality of the explanation also kept the planters unaware of the fact that economists financed the experiment.
} 
planters worked the same number of hours as a regular workday and were monitored in the same way.

\section{Data Analysis}

Table 1 presents descriptive statistics of the main variables of our experiment. As discussed in Section 2, the piece-rate on both blocks was kept constant at $0.16 \$$ during the control and treatment periods and was increased retroactively to $0.20 \$$ during the post treatment period. We next present statistics separately for control, trial, and post trial periods on both the short and long blocks. Average earnings during the trial periods are reported in the table on the basis of the initial piece-rate $(0.16 \$)$ and thus do not take into account the retro-active increase of the piece-rate.

Planting on the short block during the control and trial periods lasted two consecutive days while planting during the post trial period lasted four days. The same 15 planters worked during all three periods. While all 15 planters worked both days of the control and trial periods, the number of days spent working during the post trial period varied across planters - 10 planters worked all 4 days, 4 planters worked 3 days, and one planter worker a single day.

We measure planter productivity using their daily number of trees planted. Average planter productivity during the control period on the short block was 1667 trees per day. This number dropped to 1565 trees per day during the trial period. A Mann-Whitney test suggests that this drop is not significant at conventional levels, suggesting small and insignificant strategic behavior on the part of workers. Average productivity during the post trial period was 1910 trees per day. Mann-Whitney tests indicate that productivity during the post trial period is greater than productivity during the trial period ( $p$-value $=0.003$ ) and also during the control period $(p$-value $=0.034)$. In the next section we will extend our statistical analysis to control for extraneous factors on productivity, such as temperature and rainfall.

Planting on the long block during the control, trial, and post trial periods lasted 5, 3, and 10 days respectively. Planters varied with respect to the number of days worked during each of the three periods. Planters worked between 1 and 5 days under the control conditions, and between 2 and 3 days during the trial period, and between 12 and 17 days during the post trial period. Average daily worker productivity during the control period on the long block was 1821 trees. Productivity significantly dropped to 1245 during the trial period (Mann-Whitney test, $p$-value $=0.000)$. This suggests the existence of important ratchet effects. We note that the drop in productivity during trial period is greater on the long block 
than on the short block. This is consistent with workers having more incentives to reduce output during trial on the long block since they can benefit from a (potential) piece-rate increase for a longer period of time. Productivity during the post trial period on the long block significantly increased to 1649 trees per day relative to the trial period (Mann-Whitney test, $p$-value $=0.000)$. Interestingly, the level of productivity during the post trial period remained significantly below productivity during the control period (Mann-Whitney test, $p$-value $=0.015)$. This productivity decrease occurred despite workers receiving a higher piece-rate during the post trial period than during the control period.

While the general conditions of the terrain are kept constant across all three periods of the experiment, planting conditions may have been affected by varying weather conditions. To account for weather effects we collected data on maximum and minimum daily temperatures as well as daily rainfall in proximity to all blocks. We find that average minimal daily temperatures varied by approximately 2 degrees across periods. There is a slightly higher variation in the average maximum daily temperatures across periods. We find that the trial period on the short block coincided with the highest maximal temperatures (approximately 5 degrees (Celsius) higher than during the control period) while the trial period on the long block coincides with the lowest average maximal temperatures (approximately 5 degrees (Celsius) lower than during the control period). Finally, the control period on the short block and the trial period on the long block received more rain than did other periods. We will take the possible effects of weather on productivity into account when analyzing the effects of incentives on productivity during our experiment.

To measure the importance of commitment in an unrestricted framework we specify the following linear panel data regression model

$$
\text { trees }_{i t}=\mathbf{x}_{i t}^{\prime} \boldsymbol{\beta}+\alpha_{i}+\lambda_{t}+\varepsilon_{i t}
$$

where trees $_{i t}$ denotes the daily number of trees planted on day $t$ by planter $i, \mathbf{x}_{i t}$ denotes a vector of exogenous variables, $\alpha_{i}$ denotes a planter-specific, time-invariant productivity parameter, $\lambda_{t}$ capture day-specific conditions, and $\varepsilon_{i t}$ denotes unobservable factors which vary across days and planters. We treat $\alpha_{i}$ as planter fixed effects while the composite term $\lambda_{t}+\varepsilon_{i t}$ is treated as a random effect assumed to be mean independent of the other variables entering the model.

We consider two specifications of this model, which differ with respect to the variables in $\mathbf{x}_{i t}$. Our baseline model specifies $\mathbf{x}_{i t}$ as a function of a Trial binary variable taking a value of 1 when planting occurs during the trial period on the treatment block ( 0 otherwise), a Post trial binary variable taking a value of 1 when planting occurs during the post trial period on 
the treatment block (0 otherwise), and three weather variables (daily maximal temperature, daily minimal temperature, and daily rainfall).

We highlighted in section 2 the possibility that planters coordinate their efforts better on the second day (and the third day for the long block) of the trial period. Our extended specification is specified to test whether ratchet effects are different between first day and the other days spent working under treatment conditions. We do so by adding interaction terms between Trial and dummy variables indicating the second and (for the long block) third days of work under the trial conditions.

Table 2 presents the results for both specifications. The first two columns of the table contain the results of both specifications obtained by pooling data from both blocks. We find that productivity during the trial period is significantly lower than during the control period (or reference category) by an average of 359 trees per planter per day. This represents a $19 \%$ productivity decrease relative to the control period during which the firm was committed to the piece rate. We do not find that productivity during the post-trial period differs significantly from productivity under control, an indication that workers increased their productivity (relative to the trial period) after the piece-rate was increased. Results from the extended specification do not suggest that behavior during trial differed across the days of the trial. In particular, interactions of Trial with the dummy variables for the days of work during trial are not individually significant at conventional levels.

The remainder of the table presents results for each block, separately. We find that average daily planter productivity during the trial period on the short block is 265 trees lower than during the control period $(p$-value $=0.035)$. This represents a decrease in productivity of $15.25 \%$ relative to the control period. Our extended specification for the short block reveals that workers withheld output mostly during the second day of work during the trial period. In particular, the leading treatment variable is not significantly different from zero while average productivity during the second day of trial is predicted to be 329 trees lower than during the control period $(p$-value $=0.023)$. These results are consistent with workers being able to coordinate better their actions after the first day of trial.

Results for the baseline specification on the long block reveal substantially stronger ratchet effects. We find that average daily worker productivity is predicted to be 571 trees lower during the trial period than during the control period $(p$-value $=0.000)$. This represents a decrease in productivity of of $39.6 \%$ relative to the control period, approximately twice the size of the effect measured on the short block.

The behaviour of workers during the post-trial period is more mixed in terms of supporting the model's predictions. In general, average daily worker productivity during the post-trial 
period is significantly greater than during the trial period, which confirms that workers took advantage of the increased piece rates to earn rents. However, productivity is not significantly greater than during the control period. This suggests that workers did not reveal true conditions during the post-trial period as predicted by the model. In failing to do so, they forwent some rents. This may be due to the fact that workers were reluctant to reveal to the firm that they had acted untruthfully during the trial period in order to induce an increase in the piece rate, perhaps fearing future repercussions from doing so. ${ }^{6}$

The leading Trial variable in our extended specification is negative and significant, suggesting that workers on the long block withheld output during the first day of trial (by 544 trees). This differs from results on the short block where we found no significant differences in productivity between the first day of trial relative to the control period. This difference can be explained by at least two factors. First, workers on the long block may have been reacting individually more to the absence of contractual commitment during the first day of trial given the higher potential benefits of doing so. Second, coordination between workers on the first day of trial may have been more feasible on the long block given the relatively smaller crew size. Finally, we find that average worker output was significantly lower during the second day of trial than on the first (by 85 trees). This is again consistent with workers coordinating to reduce output.

Our data contains limited background variables on workers, including their age and their number of ongoing years of tenure with the firm. Average age of workers in our experiment is 28.7, with a minimum age of 19 and a maximum age of 46 . The average number of years of tenure of workers in the experiment is 2.7 , with a minimum of 1 and a maximum of 11 . We next explore the relationship between these variables and behavior during the trial period. We do so by adding interactions between these variables and our trial variable. Table 3 presents the results. We find that age and tenure do not significantly affect behavior during the trial period on the short block. However, we find a significant positive effect of age on productivity during trial on the long block. This suggests that older workers withheld less output than younger workers during trial. As with the short block, we find that tenure has no significant effect on productivity during trial on the long block.

\footnotetext{
${ }^{6}$ Income effects or reference dependent preferences may also play a role. Income effects would imply that workers substitute effort for on-the-job leisure as the firm raises the piece-rate paid. Reference-dependent preferences imply that the marginal utility of income decreases once earnings exceed a worker-specific target.
} 


\section{Conclusion}

We provided direct evidence that contractual commitment and worker turnover can be effective to deal with the negative effects of workers behaving strategically in the presence of moral hazard. In particular, removing contractual commitment reduced overall worker average output by $19 \%$. Moreover, workers withheld output more the the greater they could benefit from their perceived information asymmetry. Overall, the loss in productivity associated with removing contractual commitment represented between $15 \%$ and $40 \%$ of productivity levels measured under contractual commitment.

An intriguing finding has been that workers continued to withhold output beyond the trial period in the experiment. This output reduction is also sizeable and reached at least $16 \%$ on the long treatment block. It is noteworthy that this reduction in output occurred despite workers knew the firm would return to its normal practice of maintaining contractual commitment on future blocks. Hence, this output reduction cannot be explained by workers strategically trying to influence their future compensation. We highlighted at least three possible mechanisms to explain this behavior: income effects, income targeting, and apprehension of future sanctions. Disentangling these mechanisms merits further analysis. Regardless of the mechanism however, our results suggest that removing contractual commitment will affect negatively worker behavior even after the firms raises worker compensation in order to increase their productivity. 


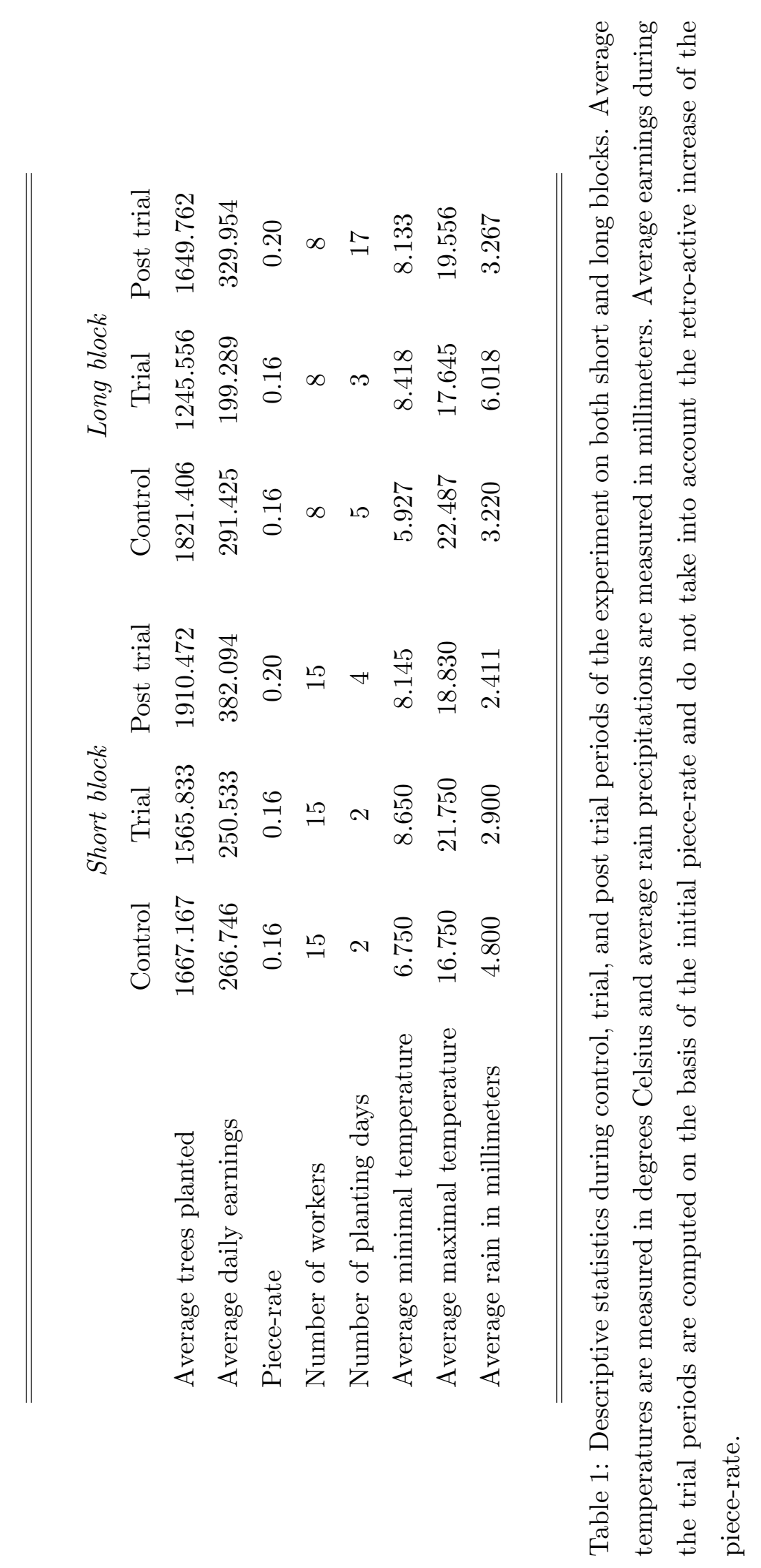




\begin{tabular}{|c|c|c|c|c|}
\hline \multirow[b]{2}{*}{ Constant } & \multicolumn{2}{|c|}{ Short block } & \multicolumn{2}{|c|}{ Long block } \\
\hline & $\begin{array}{c}1737.900 * * * \\
(132.229)\end{array}$ & $\begin{array}{c}1723.259^{* * *} \\
(188.765)\end{array}$ & $\begin{array}{c}1442.826^{* * *} \\
(143.494)\end{array}$ & $\begin{array}{c}1457.678^{* * *} \\
(149.135)\end{array}$ \\
\hline Trial & $\begin{array}{c}-265.716^{* *} \\
(101.993)\end{array}$ & $\begin{array}{c}-42.617 \\
(103.230)\end{array}$ & $\begin{array}{c}-571.508^{* * *} \\
(46.278)\end{array}$ & $\begin{array}{c}-544.973^{* * *} \\
(37.749)\end{array}$ \\
\hline Trial $\times$ day 2 & & $\begin{array}{c}-329.186^{* *} \\
(113.371)\end{array}$ & & $\begin{array}{c}-96.029 * * \\
(38.331)\end{array}$ \\
\hline Trial $\times$ day 3 & & & & $\begin{array}{l}-22.209 \\
(13.418)\end{array}$ \\
\hline Post trial & $\begin{array}{l}-56.363 \\
(90.331)\end{array}$ & $\begin{array}{c}-18.563 \\
(105.048)\end{array}$ & $\begin{array}{c}-233.551^{* * *} \\
(47.121)\end{array}$ & $\begin{array}{c}-239.440^{* * *} \\
50.833\end{array}$ \\
\hline Maxtemp & $\begin{array}{l}-36.683 \\
(20.577)\end{array}$ & $\begin{array}{l}-51.108 \\
(20.642)\end{array}$ & $\begin{array}{c}-6.711 \\
5.931\end{array}$ & $\begin{array}{l}-7.764 \\
(6.366)\end{array}$ \\
\hline Mintemp & $\begin{array}{c}149.211^{* *} \\
(53.272)\end{array}$ & $\begin{array}{c}174.336^{* *} \\
(53.361)\end{array}$ & $\begin{array}{c}21.078^{* * *} \\
6.308\end{array}$ & $\begin{array}{c}22.436^{* * *} \\
(7.001)\end{array}$ \\
\hline Rain & $\begin{array}{l}-33.840 \\
(27.910)\end{array}$ & $\begin{array}{l}-15.885 \\
(28.582)\end{array}$ & $\begin{array}{c}-11.944^{* * *} \\
(3.407)\end{array}$ & $\begin{array}{c}-12.209^{* * *} \\
(3.651)\end{array}$ \\
\hline$R$-square & 0.858 & 0.869 & 0.817 & 0.819 \\
\hline
\end{tabular}

Table 2: Regression results for the short and long blocks. Dependent variable is number of tress planted per day per worker. Individual planter fixed effects were included in all regressions but are omitted from the table. Numbers in parenthesis represent clustered standard errors (at the day level) and are robust to arbitrary forms of heteroscedasticity. 

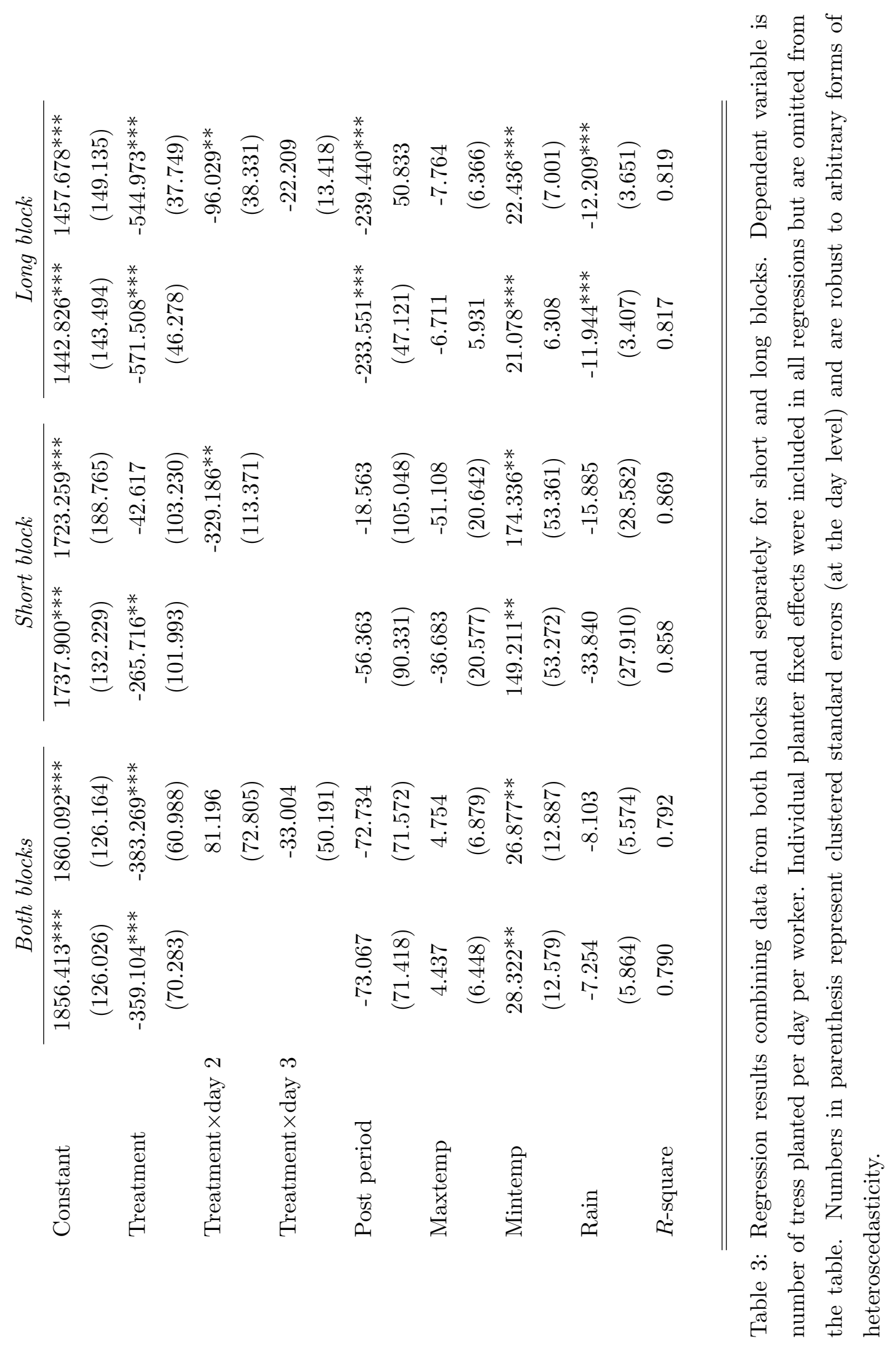


\section{References}

Baron, D., and D. Besanko (1987): "Commitment and Fairness in a Dynamic Regulatory Relationship," Review of Economic Studies, 54, 413-436.

Charness, G., P. Kuhn, and M.-C. Villeval (2011): "Competition and the Ratchet Effect," Journal of Labor Economics, 29, 513-547.

Gibbons, R. (1987): "Piece-Rate Incentive Schemes," Journal of Labor Economics, 5, 413429.

Gneezy, U., And J. List (2006): "Putting Behavioral Economics to Work: Field Evidence on Gift Exchange," Econometrica, 74, 1365-1384.

ICKes, B., And L. Samuelson (1987): "Job Transfers and Incentives in Complex Economic Organizations: Thwarting the Ratchet Effect," RAND Journal of Economics, 18, 275-286.

Kanemoto, Y., and W. MacLeod (1992): "The Ratchet Effect and the Market for Secondhand Workers," Journal of Labor Economics, 10, 85-98.

Laffont, J.-J., And J. Tirole (1988): "The Dynamics of Incentive Contracts," Econometrica, 56, 1153-1175.

LazeAr, E. (1986): "Salaries and Piece Rates," Journal of Business, 59, 405-431.

Levenson, A., C. Zoghi, M. Gibbs, and G. Benson (2011): "Optimizing Incentive Plan Design: A Case Study," IZA Discussion paper No. 5985.

Macartney, H. (2011): "The Dynamic Effects of Educational Accountability," Working paper, Duke University.

Weitzman, M. (1980): "The Ratchet Principle and Performance Incentives," Bell Journal of Economics, 11, 302-308. 